Purdue University

Purdue e-Pubs

RCHE Publications

Regenstrief Center for Healthcare Engineering

8-17-2004

\title{
Information technology for detecting medication errors and adverse drug events
}

James G. Anderson

Purdue University, andersonj@purdue.edu

Follow this and additional works at: http://docs.lib.purdue.edu/rche_rp

Anderson, James G., "Information technology for detecting medication errors and adverse drug events" (2004). RCHE Publications. Paper 41.

http://docs.lib.purdue.edu/rche_rp/41

This document has been made available through Purdue e-Pubs, a service of the Purdue University Libraries. Please contact epubs@purdue.edu for additional information. 


\section{Expert Opinion}

1. Introduction

2. Medication errors and adverse drug events

3. A systems approach to medication errors

4. Detection of adverse drug events using information technology

5. Expert opinion and conclusion

\title{
Information technology for detecting medication errors and adverse drug events
}

\author{
James G Anderson \\ Department of Sociology \& Anthropology, Purdue University, West Lafayette, IN 47907, USA
}

It is estimated that over three-quarters of a million people are injured or die in hospitals each year from adverse drug events (ADEs). The majority of medical errors result from poorly designed healthcare systems rather than from negligence on the part of healthcare providers. In general, healthcare systems rely on voluntary reporting, which seriously underestimates the number of medication errors and ADEs by as much as $90 \%$. This paper reviews the causes and impact of medication errors and ADEs. It also reports studies that have used information technology (IT) to detect and prevent medication errors and ADEs. Significant reduction of medication errors and ADEs requires systemic implementation of IT, improvements in the reporting of errors, and integration of the components of the healthcare systems' information systems. At the present time, most healthcare systems should be able to use IT to detect and prevent ADEs.

Keywords: adverse drug events (ADEs), information technology (IT), medication errors

Expert Opin. Drug Saf. (2004) 3(5):

\section{Introduction}

Studies dating back to 40 years ago indicate that a substantial number of patients suffer adverse events while they are hospitalised [1-5]. Recently, the Institute of Medicine (IOM) report [6] estimated that 44,000 - 98,000 hospitalised patients die in the USA each year due to medical errors. Medical errors rank between the fourth and seventh leading cause of death, exceeding deaths from automobile accidents, AIDS and breast cancer.

Two studies of the incidence and types of adverse events occurring in US hospitals in New York State, Utah and Colorado have reached similar conclusions. The New York State study found that 3.7\% of hospitalised patients suffered adverse events [4]. Adverse events occurred in $2.9 \%$ of hospitalised patients in both Utah and Colorado [7-8]. In New York State, $13.6 \%$ of the adverse events resulted in the patient's death; in Colorado and Utah, $8.8 \%$ of patients who suffered adverse events died as a result. The Utah and Colorado study estimated that the total annual cost of adverse events for these two states was $\$ 662$ million, while the cost of preventable adverse events was $\$ 308$ million. For the nation as a whole, the total cost resulting from preventable adverse events was estimated to be $\$ 17-29$ billion per year.

Of the adverse events identified in the Utah and Colorado study, $45 \%$ resulted from operative procedures. Drug errors accounted for $19 \%$ of adverse events. The New York State study also found that drug-related errors accounted for 19\% of adverse events in hospitalised patients. Johnson and Bootman [9] estimated the annual cost for the USA of morbidity and mortality due to drug therapy in 1995 to be $\$ 76.6$ billion.

This paper reviews the literature on: (1) the incidence and costs of medication error-related adverse drug events (ADEs); (2) systems analyses of the causes of 
medication errors and ADEs; and (3) the use of information technology (IT) to detect ADEs; and concludes that tools are available to detect and reduce the number of ADEs in healthcare settings. The following journals were searched for articles on the use of IT to promote drug safety: Journal of the American Medical Informatics Association, International Journal of Medical Informatics, JAMA, NEJM, Lancet, BMJ, Archives of Internal Medicine, and Drug Safety, among others.

\section{Medication errors and adverse drug events}

Not all medication errors result in ADEs. A study by Bates et al. [10] found 530 medication errors out of 10,070 drug orders. A total of $40 \mathrm{ADEs}$ were detected. This translated into $\sim 1 \mathrm{ADE}$ in 100 medication errors, while 7 in 100 errors had the potential to cause an ADE.

In addition, medication-related errors that may result in ADEs are frequent among hospitalised patients as well as among out-patients. One study found preventable ADEs in 2 out of every 100 patients admitted to the hospital [11]. The study estimated that each ADE increased the cost of hospitalisation by $\$ 4,700$. For a 700-bed hospital, the increased cost due to ADEs was estimated to be $\$ 2.8$ million annually or $\$ 2$ billion for the USA as a whole. A study of out-patients also found a rate of 5.5 ADEs per 100 patients who visited primary care physicians associated with Brigham and Women's Hospital in Boston due to medication-related errors [12].

Determining the true rate of medication errors and ADEs has been difficult since most errors are unreported. One study focused on errors made during the dispensing and administration stages of the drug delivery system [13]. The study found that the current method of collecting data on the types and frequency of medication errors using incident reports grossly underestimates errors. Only 36 errors were reported on incident reports and 84 errors were reported on anonymous questionnaires. On the basis of direct observation, the investigators estimated that 51,200 errors would have occurred in dispensing and administering medications over a period of 59,470 patient-days. A second study was performed in an Army out-patient pharmacy [14]. In this study, prescription errors were separated from dispensing errors. The overall dispensing error rate was 3.8\%.

Manual chart review has been shown to be effective in identifying medical errors and adverse events but is costly [15]. However, direct observation can detect errors missed by chart review. One study compared the use of retrospective chart review to direct observation in detecting medication errors [16]. Chart review estimated the error rate to be $0.2 \%$. In contrast, direct observation detected an error rate of $9.6 \%$.

Detecting ADEs is also problematic. Most hospitals rely on voluntary reporting of ADEs. This practice may result in the detection and reporting of as few as 10\% of ADEs [17-20].

\section{A systems approach to medication errors}

Traditional approaches to error detection and reduction in healthcare have emphasised training, guidelines and sanctions. Medical and nursing education focuses on knowledge and adherence to protocols. Errors are treated as individual mistakes or failings and are punished largely by peer sanctions. Ultimately, healthcare provider errors may be punished through malpractice tort litigation [21].

At the same time there is growing awareness that the majority of medical errors result from poorly designed healthcare systems rather than primarily from negligence on the part of healthcare providers. Preventing and reducing medical errors and ADEs requires attention to the methods of detection used and the prevention of errors at each stage of the delivery system. Systemic modifications reduce the overall likelihood that an error will occur and permit detection and intervention before the error causes harm to a patient [22-26]. Several studies have utilised a system approach to study medication errors.

This approach is much more likely to lead to improvement in the detection and prevention of medication errors that can lead to ADEs. For example, one study of ADEs identified 16 causes of systems failure that resulted in medication errors that resulted in an ADE or had the potential to result in an ADE [24]. The highest percentage of errors that resulted in preventable ADEs was made during the ordering stage $(49 \%)$. Errors resulting in preventable ADEs were also made at all other stages; transcription (6\%), dispensing (4\%), and administration (34\%) [27]. Of all the ADEs, $1 \%$ were fatal, $12 \%$ were life-threatening, $30 \%$ were serious, and $57 \%$ were significant.

Failures in seven subsystems related to the delivery of medications accounted for $78 \%$ of the medication errors that occurred. The most frequent system failures and resulted from a lack of knowledge about drugs. A second major systems failure resulted from the unavailability of patient-specific information at the time that the prescription was written. In a number of instances the allergy defence system failed even when information concerning patient allergies had been included in the medical record. Manual transcription of physician orders was another major source of errors. Errors also occurred because of the complexity of the system used to track medications from ordering to administration.

This problem was compounded by problems in interservice communication. Information about medication errors and ADEs was not routinely provided to physicians, nurse and pharmacists. As a result, there was little follow-up to prevent a similar error from occurring again on hospital units.

The Institute for Safe Medication Practices [28] conducted a national study of the ability of hospital pharmacy systems to detect and prevent drug-related errors. The investigators found that the pharmacy system only detected about a third of these errors.

The inability of the pharmacy systems to detect errors was primarily due to systems problems. Many hospital 
information systems are not integrated. Stand-alone systems for order entry, pharmacy, and laboratories make it difficult to detect medication errors that may result in ADEs. The lack of integration also makes it difficult for providers to access drug information as well as previous patient encounter information at the time that drug orders are written. Moreover, many systems lack the capability to screen orders and alert or prompt healthcare providers when dangerous situations that could cause serious harm or death to a patient occur. Even within the medication delivery system, the prescribing, dispensing and administering stages in many instances were not electronically linked. Futhermore, dispensing and administration errors frequently occur when pharmacy systems use confusing abbreviations and generate hard-to-read labels.

Studies such as the one reported above by the Institute for Safe Medication Practices [28] suggest that piecemeal implementation of information systems may fail to detect and prevent errors. Furthermore, physician order entry systems are frequently complex and time-consuming. As a result, physicians frequently bypass many of the systems and rely on nurses, unit secretaries and pharmacists to enter orders into the information systems.

Anderson and co-workers [29] developed a simulation model to evaluate the capability of IT to detect and to prevent ADEs in hospitals. The model was used to estimate ADE rates and associated hospital costs based on five implementations of IT. These were: provision of computer-based drug information at the prescribing stage; physician computer order entry; a unit dosing system in the pharmacy; an automated medication dispensing system; and a comprehensive information system for medication delivery.

The model estimated that the various interventions, if individually implemented, would reduce ADEs by $5-13 \%$. The largest reduction in errors and adverse events from a single IT application would result from physician order entry. In comparison, the implementation of a comprehensive information system for medication delivery would result in a $28 \%$ reduction in ADEs. The estimated reduction in annual hospital costs resulting from ADEs was estimated to range $\$ 285,000$ - \$700,000 when IT was implemented piecemeal. Implementation of a comprehensive information system was estimated to save the hospital $\$ 1.5$ million/year.

\section{Detection of adverse drug events using information technology}

As the use of IT to collect, store and transmit medical data electronically becomes more widespread, this technology can be used to identify ADEs. Bates and co-workers [30] review the methodologies that use IT to detect adverse events in healthcare settings and studies that use these techniques. These tools include the collection of clinical data in electronic form, event monitoring and natural language processing. For example, pharmacy data and clinical laboratory data are usually available in coded electronic form. Also, these data are available in real-time, permitting intervention in time to prevent $\mathrm{ADEs}$ from harming patients. A number of studies have demonstrated how these data can be screened for ADEs [31-38].

Basic information systems may be effective in identifying and avoiding potential ADEs. One study classified hospital information systems into three levels [39]. Level 1 systems monitor medication orders for drug-drug interactions and drug allergy problems. These systems require only that patient demographics, results from diagnostic tests and current medications are available online. Level 2 systems, where all orders are entered online by physicians, provide additional protection for patients through drug-dose checking, cumulative dose checking, dose algorithms and detection of transcription errors. More sophisticated Level 3 systems provide all of the functional features of Level 1 and 2 systems as well as providing automated problem lists available online.

The study used chart reviews to identify adverse events experienced by patients admitted to Brigham and Women's Hospital. The investigators estimated that $53 \%$ of adverse events were identifiable with the lowest level information system. A Level 2 system would have identified $58 \%$ of adverse events and a Level 3 system, 89\%.

The more sophisticated systems are capable of detecting a much larger percentage of ADEs and potential ADEs. For example, a computerised system was developed at LDS Hospital in Salt Lake City, Utah, to monitor ADEs [31]. The system was programmed to generate a daily list of potential ADEs from data contained in an integrated hospital information system. Sudden medication stop orders, ordering of antidotes, and abnormal laboratory values were taken as signs of potential ADEs. A clinical pharmacist reviewed the medical records of all patients on the list for potential ADEs. During an 18-month period, 631 of 731 verified ADEs were detected by the automated system. At the same time only 9 ADEs were identified by the traditional reporting system.

Other investigators have developed and tested similar systems. Jha et al. [34] used a system based on the LDS hospital rules to identify ADEs. The detection rules were based on new medication orders, laboratory results above or below threshold values, and medication orders associated with changes in laboratory values. A daily list of alerts based on these rules was generated by the computer system. Subsequently, the patient's medical chart was reviewed for indication of an ADE or potential ADE.

The automated ADE detection system was compared to two other strategies used to detect ADEs, chart review and voluntary reporting. A total of $617 \mathrm{ADEs}$ were detected by at least one of the methods. The automated system detected 275 (45\%) ADEs; chart review found 398 (65\%) ADEs; and voluntary reporting detected 23 ( $4 \% \mathrm{ADEs}$ ).

Most of the information systems used to detect ADEs have been developed and implemented in in-patient hospital settings. One system was developed to detect ADEs in an ambulatory setting [12]. Patient data from an electronic medical record was used to detect ADEs. The computer system was 
programmed to search for ICD-9 codes that had been found to be associated with ADEs. A database containing the patient's medication and drug allergy lists was also scanned. A third approach to identifying ADEs was computer-event monitoring. Rules were developed to identify new medication orders, abnormal laboratory results and changes in laboratory values that had a high probability of being associated with ADEs. Finally, a data mining tool, Micromedex $\mathrm{M}^{2} \mathrm{D}_{2}$ medical data dictionary, was used to electronically examine visit notes [40].

For each incident that was identified, a chart review was used to ascertain whether or not an ADE had actually occurred. The evaluation involved a period of 1 year and a review of the electronic medical records for 23,064 patients. A total of 864 ADEs were identified. Text searching identified $91 \%$ of the ADEs; $6 \%$ were identified from the allergy records; event monitoring identified 3\%; and ICD-9 codes found only $0.3 \%$ of the ADEs.

\section{Expert opinion and conclusion}

According to the Joint Commission on Accreditation of Healthcare Organisations (JCAHO), the medication error rate is the most important indicator of the quality of the medication delivery system. It is estimated that over three-quarters of a million people are injured or die in hospitals annually from ADEs [11,41]. National hospital expenditures resulting from the treatment of persons injured by ADEs while hospitalised have been estimated to be as high as $\$ 5.6$ billion per year [8,11]. Between 1983 and 1993, deaths due to prescription errors increased by $243 \%$ [42-43].

There is considerable evidence that medication errors that result in ADEs can be detected and prevented [44]. Information systems that include physician order entry, decision support, and alerting systems can significantly reduce errors and adverse events that result in injury to or the death of patients. For example, studies have demonstrated that computerised physician order entry systems that include decision support can significantly improve the quality of medication delivery [101,45-47]. In addition, computerised alerting systems have been shown to decrease error rates, delays in treatment, length of hospital stay, and costs [48-51]. However, experience with early hospital and ambulatory care medical information systems suggests that major organisational changes are frequently required to successfully implement IT, especially physician order entry systems [52,53].

However, in order to be effective, IT must be implemented using a systems approach. Many hospitals lack an electronic medical record that is needed to implement most decision support systems. Lack of integration of physician order entry systems, pharmacy systems, and laboratory systems is another barrier to reducing medication errors.

As demonstrated by the simulation study [29], piecemeal applications of IT have only limited results in reducing ADEs and associated hospital costs. Moreover, it was estimated that even the implementation of a comprehensive information system for medication delivery would only reduce ADEs and hospital costs by $\sim 28 \%$. Computerised systems are only part of the overall solution in preventing medication errors and ADEs [54,55]. The process of reporting medication errors and ADEs needs to be significantly improved. At present, only $\sim 10 \%$ of medication errors are reported using a voluntary reporting system. Improvement in reporting will require a system where persons reporting the error do not fear punishment. Secondly, pharmacists need to be more directly integrated into the medication delivery system at every stage. Brigham and Women's Hospital was able to reduce the ADE rate in the ICU unit by two-thirds by having pharmacists participate in patient rate with the intensive care unit team [56]. This resulted in cost savings of $\$ 270,000 /$ year. Finally, nursing medication administration and monitoring systems need to be improved. This should include bar-coding of medications as well as improved labelling and warnings on medications with a high potential for harm to patients.

To date, most applications of IT to identify and prevent ADEs have focused on hospital in-patient settings. An important area for future research is the development and implementation of IT in ambulatory settings to identify and prevent adverse drug reactions. Because of the high volume of out-patient visits, IT has the potential to significantly improve the quality of healthcare and reduce costs. A recent report by the Center for Information Technology Leadership [57] estimated the universal adoption of ambulatory computerised provider order entry (ACPOE) systems that include decision support would avoid 2.1 million ADEs, saving $\$ 34$ billion/year. However, it is estimated that $<10 \%$ of physicians in the US who practice in out-patient settings currently use any type of ACPOE.

There are significant barriers to the introduction of IT into practice settings. At present, there are limited incentives for providers to invest in IT in order to detect and prevent ADEs. The Leapfrog Group, which consists of a number of Fortune 500 companies, strongly supports computer physician order entry (CPOE) as a means of reducing medical errors, especially errors that result in ADEs. In response, some payers are offering financial incentives to healthcare providers who adopt CPOE.

The President's Information Technology Advisery Committee Draft Report [58] calls for accelerated adoption of IT in the healthcare sector. They specifically recommend the adoption of: (1) electronic health records to maximise the information available to healthcare providers at the point of care; (2) computer-assisted decision support to increase compliance with evidence-based medicine; (2) electronic order entry in both out-patient and in-patient practice settings; and (4) interoperable electronic information interchange. In order to facilitate the implementation of these recommendations, President Bush has proposed \$100 million to be spent on promising health IT.

The Centers for Medicare and Medicaid services have proposed that computerised monitoring of ADEs be mandated in in-patient settings [102]. While this is an important step in the 
direction of improved patient safety, widespread adoption of the IT applications to detect and prevent ADEs will require both incentives and sanctions. Moreover, it will require a change in the current 'blame and shame' culture that pervades healthcare institutions at present [59].

\section{Acknowledgement}

I wish to acknowledge the assistance of $M$ Anderson with the preparation of this paper. Portions of this paper are taken from reference [60] with permission.

\section{Bibliography}

Papers of special note have been highlighted as either of interest $(\bullet)$ or of considerable interest $(\bullet \bullet)$ to readers.

\section{SCHIMMEL EM:}

The hazards of hospitalization. Ann. Intern. Med. (1964) 60:100-110.

2. STEEL K, GERTMAN PM, CRESCENZI C et al: : Iatrogenic illness on a general medical service at a university hospital. N. Engl. J. Med. (1981) 304:638-642.

3. BEDELL SE, DEITZ DC, LEEMAN D, DELBANCO TL:

Incidence and characteristics of preventable iatrogenic cardiac arrests. JAMA (1991) 265:2815-2820.

4. BRENNAN TA, LEAPE LL, LAIRD NM et al: : Incidence of adverse events and negligence in hospitalized patients. N. Engl. J. Med. (1991) 324:370-376.

5. LEAPE LL, BRENNAN TA, LAIRD N et al:: The nature of adverse events in hospitalized patients: results of the Harvard medical practice study II. N. Engl. J. Med. (1991) 324:377-384.

6. KOHN LT, CORRIGAN JM, DONALDSON MS (Eds): In: To Err is Human: Building a Safer Health System. National Academy Press, Washington, DC (1999).

7. THOMAS EJ, STUDDERT DM, BURSTEIN HR et al:: Incidence and types of adverse events and negligent care in Utah and Colorado. Med. Care (2000) 28:261-271.

8. THOMAS EJ, STUDDERT DM, NEWHOUSE JP et al:: Costs of medical injuries in Utah and Colorado. Inquiry (1999) 36:255-264.

9. JOHNSON JA, BOOTMAN JL: Drug-related morbidity and mortality: a cost of illness model. Arch. Intern. Med. (1995) 155:1949-1956.

10. BATES DW, BOYLE DL, VANDERVLIET MB et al.:

Relationship between medication errors and adverse drug events. J. Gen. Intern. Med. (1995) 274:29-34.
11. BATES DW, SPELL NS, CULLEN DJ et al: : The costs of adverse drug events in hospitalized patients. JAMA (1997) 277:307-311.

- A detailed study of the costs of ADEs in hospitalised patients.

12. HONIGMAN B, LEE J, ROTHSCHILD J et al:: Using computerized data to identify adverse drug events in outpatients. J. Am. Med. Inform. Assoc. (2001) 8:254-266.

- A detailed evaluation of the use of IT to identify ADEs in an ambulatory setting.

13. BARKER KN, ALLAN EL: Research on drug-use-system errors. Am. J. Health Syst. Pharm. (1995) 52:400-403.

14. BUCHANAN TL, BARKER KN, GIBSON JT et al: : Illumination and errors in dispensing. Am. J. Hosp. Pharm. (1991) 48:2137-2145.

15. BRENNAN TA, LOCALIO AR, LEAPE LL et al: : Identification of adverse events occurring during hospitalization: A cross-section study of litigation, quality assurance and medical records at two teaching hospitals. Ann. Intern. Med. (1990) 112:221-226.

16. SHANNON RC, DE MUTH JE: Comparison of medication-error detection methods in the long term care facility. Consult. Pharm. (1987) 2:148-151.

17. BERRY LL, SEGAL R, SHERRIN TP, FUDGE KA: Sensitivity and specificity of three methods of detecting adverse drug relations. Am. J. Hosp. Pharm. (1988) 45:1534-1539.

18. O'NEIL AC, PETERSEN LA, COOK EF et al: : A comparison of physicians self-reporting with medical record reviews to identify medical adverse events. Ann. Intern. Med. (1993) 119:370-376.

19. CHRISCHILLES EA, SEAGER ET, WALLACE RB: Self-reported adverse drug reactions and related resource use. Ann. Intern. Med. (1992) 117:634-640.

20. CULLEN DJ, BATES DW, SMALL SD et al: : The incident reporting system does not detect adverse drug events: a problem for quality improvement. J. Qual. Improv. (1995) 21:541-548.
21. LEAPE LL: Error in Medicine. JAMA (1994) 272:1851-1868.

22. BOGNER MS (Ed.): In: Human Error in Medicine. Lawrence Erlbaum, Hillsdale, NJ (1994).

23. MORAY N: Error reduction as a systems problem. In: Human Error in Medicine. Bogner MS (Ed.), Lawrence Erlbaum, Hillsdale, NJ (1994):67-92.

24. LEAPE LL, BATES DW, CULLEN DJ et al:: Systems analysis of adverse drug events. JAMA (1995) 274:35-43.

- Systems analysis of the causes of ADEs in hospital settings.

25. BERWICK DM: A primer on leading the improvement of systems. Br. Med. J. (1996) 312:619-623.

26. ELSON RB, FAUGHNAN JG, CONNELLY DP: An industrial process view of information delivery to support clinical decision making: implications for systems design and process measures. J. Am. Med. Inform. Assoc. (1997) 4:266-278.

27. BATES DW, CULLEN DJ, LAIRD N et al: Incidence of adverse drug events and potential adverse drug events. JAMA (1995) 274:29-34.

28. INSTITUTE FOR SAFE MEDICATION PRACTICES: Over-reliance on computer systems may place patients at great risk. ISMP Medication Safety Alert, Feb. 12, 1999. Huntingdon Valley, PA, ISMP (1999).

- National study of the ability of computerised hospital pharmacy systems to prevent drug-related errors.

29. ANDERSON JG, JAY SJ, ANDERSON MM, HUNT TJ: Evaluating the capability of information technology to prevent adverse drug events: a computer simulation approach. J. Am. Med. Inform. Assoc. (2002) 9:479-490.

- Simulation used to evaluate IT applications designed to detect and prevent ADEs.

30. BATES DW, EVANS RS, MURFF $\mathrm{H}$, STETSON PD, PIZZIFERRI L, HRIPCSAK G: Detecting adverse events using information technology. J. Am. Med. Inform. Assoc. (2003) 10:115-128. 
-• Review of methodologies using IT technology to detect ADEs.

31. CLASSEN DC, PESTOTNIK SL, EVANS RS, BURKE JP:

Computerized surveillance of adverse drug events in hospital patients. JAMA (1991)

266:2847-2851.

- Evaluation of computerised ADE monitoring to detect potential ADEs occurring in hospital patients.

32. EVANS RS, PESTOTNIK SL, CLASSEN DC et al:: Preventing adverse drug events in hospitalized patients. Ann. Pharmacother. (1994) 28:523-527.

33. WHIPPLE JK, QUEBBEMAN EJ, LEWIS KS et al: Identification of patient controlled analgesia overdoses in hospitalized patients: a computerized method of monitoring adverse events. Ann. Pharmacother. (1994) 28:655-658.

34. JHA AK, KUPERMAN GJ, TEICH JM et al:: Identifying adverse drug events: development of a computer-based monitor and comparison with chart review and stimulated voluntary report. J. Am. Med. Inform. Assoc. (1998) 5:305-314.

35. LEVY M, AZAZ-LIVSHITS T, SADAN B et al:: Computerized surveillance of adverse drug reactions in hospital implementation. Eur. J. Clin. Pharmacol. (1999) 54:887-892.

36. BAGHERI H, MICHEL F, LAPEYRE-MESTRE $M$ et al: Detection and incidence of drug-induced liver injuries in hospital: a prospective analysis from laboratory signals. $\mathrm{Br}$. J. Clin. Pharmacol. (2000) 50:479-484.

37. DORMANN H, MUTH-SELBACH U, KREBS S et al: : Incidence and costs of adverse drug reactions during hospitalization: computerized monitoring versus stimulated spontaneous reporting. Drug Saf. (2000) 22(2):161-168.

38. PAYNE TH, SAVARINO J, MARSHALL R, HOEY CT: Use of a clinical event monitor to prevent and detect medication errors. Proceedings of the AMIA Symposium (2000):640-644.

39. BATES DW, O'NEIL AC, BOYLE D et al.: Potential identifiability and preventability of adverse events using information systems. J. Am. Med. Inform. Assoc. (1994) 1:404-411.

40. HONIGMAN B, LEE J, ROTHSCHILD J et al.: A computerized method for identifying incidents associated with adverse drug events in outpatients. Int. J. Med. Inf. (2001) 61(1):21-32.
41. CLASSEN DC, PESTOTNIK SL, EVANS RS et al:: Adverse drug events in hospitalized patients: excess length of stay, extra costs, and attributable mortality. JAMA (1997) 277:301-306.

42. PHILLIPS DP, BREDDER CC: Morbidity and mortality from medical errors: an increasingly serious public health problem. Annu. Rev. Public Health (2002) 23:135-150.

43. PHILLIPS DP, CHRISTENFELD N, GLYNN LM: Increase in US medication-error deaths between 1983 and 1993. Lancet (1998) 351:643-644.

44. AGENCY FOR HEALTHCARE RESEARCH AND QUALITY: Reducing and Preventing Adverse Drug Events to Decrease Hospital Costs. Research in Action, Issue 1. AHRQ Publication Number 01-0020, March 2001. Rockville, MD.

45. BATES DW, LEAPE LL, CULLEN DJ: Effect of computerized physician order entry and a team intervention on prevention of serious medication errors. JAMA (1998) 280:1311-1316.

-. Study of the use of IT to prevent ADEs in hospital settings.

46. BATES DW, TEICH JM, LEE J et al: The impact of computerized physician order entry on medication error prevention. J. Am. Med. Inform. Assoc. (1999) 6:313-321.

47. BATES DW, MILLER EB, CULLEN DJ et al: : Patient risk factors for adverse drug events in hospitalized patients. Arch. Intern. Med. (1999) 159:2553-2560.

48. EVANS RS, PESTOTNIK SL, CLASSEN DC et al: : A computer-assisted management program for antibiotics and other anti-infective agents. N. Engl. J. Med. (1998) 338:232-238.

49. TATE K, GARDNER RM, WEAVER LK: A computerized laboratory alerting system. MD Comput. (1990) 6:296-301.

50. RIND D, SAFRAN C, PHILLIPS RS et al:: Effect of computer-based alerts on the treatment and outcomes of hospitalized patients. Arch. Intern. Med. (1994) 154:1511-1517.

51. KUPERMAN G, BOYLE D, JHA AK et al: : How promptly are inpatients treated for critical laboratory results? J. Am. Med. Inform. Assoc. (1998) 5:112-119.

52. SHABOT M, LOBUE M:

Real-time wireless decision support alerts on a palmtop PDA. Proc. Annu. Symp.
Comput. Appl. Med. Care (1995) 19:174-177.

53. ANDERSON JG: Clearing the way for physicians' use of clinical information systems. Commun. ACM (1997) 40:83-90.

54. ANDERSON JG: Increasing the acceptance of clinical information systems. MD Comput. (1999) 16:62-65.

55. BATES DW: Medication errors: How common are they and what can be done to prevent them? Drug Saf. (1996) 5:303-310.

56. BATES DW, COHEN M, LEAPE LL et al: Reducing the frequency of errors in medicine using information technology. J. Am. Med. Inform. Assoc. (2001) 8:299-308.

57. LEAPE LL, CULLEN DJ, CLAPP MD et al.: Pharmacist participation on physician rounds and adverse drug events in the intensive care unit. JAMA (1999) 272:267-270.

58. JOHNSTON D, PAN E, WALKER J, BATES DW, MIDDLETON B: Center for Information Technology Leadership: Patient Safety in the Physician's Office: Assessing the Value of Ambulatory CPOE. California HealthCare Foundation (2004).

- Assessment of the value of ACPOE systems in reducing ADEs.

59. HEALTH CARE FINANCING ADMINISTRATION: Medicare and Medicaid Programs; hospital conditions of participation; provider agreements and supplier approval. Fed. Regist. (1997) 62(244):66726-66757.

60. BATES DW, EVANS RS, MURFF H, STETSON PD, PIZZIPERRI L, HRIPCSAK G: Policy and the future of adverse drug event detection using information technology. J. Am. Med. Inform. Assoc. (2003) 10:226-228

61. ANDERSON JG: A systems approach to preventing adverse drug events. In: Information Technology Business Models for Quality Health Care: An EU/US Dialogue. Krishna S, Balas EA, Boren SA (Eds), IOS Press, Amsterdam (2003):95-102.

\section{Websites}

101 http://www.ahrq.gov/qual/aderia/ aderia.htm

102 www.nitrd.gov/pitac President's Information Technology Advisory Committee, Health Care Delivery and Information Technology (HIT) Subcommittee: Draft Recommendations. April 13, 2004. 


\section{Affiliation}

James $\mathrm{G}$ Anderson $\mathrm{PhD}$

Fellow, American College of Medical Informatics,

Professor of Medical Sociology, Department of Sociology \& Anthropology, Purdue University, West Lafayette, IN 47907, USA

Tel: +1 765494 4703; Fax: +1 765496 1476;

E-mail: Andersonj@soc.purdue.edu 